\title{
ZONAS ÚMIDAS NAS BACIAS DOS RIOS MURUCUTU E AURÁ PARA IDENTIFICAR ÁREAS SUSCETÍVEIS A CONTAMINANTES
}

Leonardo Sousa dos Santos ${ }^{1}$, Carlos Benedito Barreiros Gutierrez ${ }^{2}$, Nayara de Miranda Dias ${ }^{3}$, Lucieta Guerreiro Martorano ${ }^{4}$, Altem Nascimento Pontes ${ }^{5}$

1 Geógrafo. Mestrando do Programa de Pós-Graduação em Ciências Ambientais. Universidade do Estado do Pará (UEPA). leonardocbmpa@yahoo.com.br, Belém-

Pará-Brasil

2 Mestrando do Programa de Pós-Graduação em Ciências Ambientais. Universidade do Estado do Pará (UEPA)

3 Mestrando do Programa de Pós-Graduação em Ciências Ambientais. Universidade do Estado do Pará (UEPA)

4 Pesquisadora da Embrapa Amazônia Oriental e Professora do PPGCA/UEPA, Belém, Pará

5 Professor e Pesquisador do Programa de Mestrado em Ciências Ambientais da Universidade do Estado do Pará (PPGCA/UEPA)

Recebido em: 08/04/2016 - Aprovado em: 30/05/2016 - Publicado em: 20/06/2016 DOI: 10.18677/Enciclopedia_Biosfera_2016_144

\section{RESUMO}

O objetivo neste trabalho foi identificar zonar úmidas nas bacias hidrográficas dos rios Murucutu e Aurá (BHMA) para identificar áreas suscetíveis a contaminantes. Técnicas de manipulação e análises de dados matriciais de Modelo Digital de Elevação (MDE) permitiram a delimitação de áreas úmidas em decorrência de enchente e/ou alagamento. Características físicas da bacia (declividade, uso e cobertura do solo e altimetria) foram usadas em álgebra de mapas em Sistema de Informação Geográfica (SIG). A partir de critérios de ponderação foram gerados novos planos de informação (PIs). Fez-se a reclassificação nos planos de informação gerados e atribui-se pesos para aplicação do método de Análise Hierárquica Ponderada (AHP). Os pressupostos metodológicos de geomática possibilitaram a delimitação de zonas com muito alta e alta umidade. Os resultados apontaram que cerca de $56 \%$ dessas bacias estão suscetíveis a contaminantes, principalmente pelo chorume que apresenta pode ser transportado pelo lixão do Aurá. Conclui-se que como mais da metade da BHMA possui zonas com muito alta e alta umidade, os efeitos decorrentes de contaminantes pode ser intensificado em eventos de chuvas extremas e marés altas. O ponto de conexão entre as duas bacias evidencia que 0 transporte de contaminantes pode ameaçar os mananciais de Bolonha e Água Preta que abastecem Belém e Ananindeua.

PALAVRAS-CHAVE: álgebra de mapas, análise especial, AHP, SRTM

\section{WET ZONES IN THE MURUCUTU AND AURÁ RIVER BASINS TO IDENTIFY AREAS SUSCEPTIBLE TO CONTAMINANTS}

\author{
ABSTRACT \\ This study aimed to identify wet zones in the Murucutu and Aurá river basins (BHMA) \\ to identify areas susceptible to contaminants. Digital elevation model (DEM) data
}


handling and analysis techniques enabled delimiting the wet areas due to flood and/or overflow. The basin's physical characteristics (declivity, soil use and cover, and altimetry) were used in map algebra in a Geographic Information System (GIS). New information plans (IPs) were generated from weighting criteria. The information plans generated were reclassified and weight was attributed to the application of the Weighted Hierarchical Analysis (WHA) method. The methodological assumptions of geomatics enabled delimiting the zones with high and very high humidity. The results indicated that about $56 \%$ of these basins are susceptible to contaminants, particularly by slurry that seems to be transported from Aurá landfill. It is concluded that, since over half of the BHMA has zones with high and very high humidity, the effects derived from contaminants may be augmented during extreme rainfall and high tides. The connection point between the two basins shows that contaminant transport may threaten the water collection sites of Bolonha and Água Preta that supply the cities of Belém and Ananindeua.

KEYWORDS: map algebra, spatial analysis, WHA, SRTM

\section{INTRODUÇÃO}

O processo de ocupação urbana, aliado a falta de planejamento de urbanização das cidades, tem como uma das principais consequências o aumento dos problemas relacionados às inundações e/ou alagamentos (SANTOS \& ROCHA, 2013). A identificação de áreas alagadas e/ou sujeitas à inundação para ações de planejamento e tomadas de decisão, através de álgebra de mapas, vem a contribuir no sentido de facilitar a delimitação de regiões consideradas de risco de contaminação por doenças veiculadas por meios hídricos (SANTOS \& ROCHA, 2013; MELO et al., 2015).

As áreas alagadas e/ou sujeitas à inundação neste trabalho são consideradas com áreas úmidas, caracterizadas como território extremamente plano, com declividade mínima, o que faz com que o nível da lâmina d'água permaneça acima da superfície durante a maioria dos meses do ano (PIEDADE et al., 2014). De acordo com STEINKE (2008), as áreas úmidas são também áreas constituídas por águas represadas em terra firme, terrenos da calha normal dos rios, áreas com acumulação de água por drenagem, caracterizadas por águas elevando-se de forma paulatina e previsível durante um período de tempo.

ARAÚJO et al. (2010), afirmam que as técnicas de manipulação e análises de dados matriciais de Modelo Digital de Elevação (MDE) podem identificar áreas propícias a enchente e/ou alagamento (úmidas). Neste contexto, desde ano de 2015 mais de 110 famílias ribeirinhas que moram no entorno das bacias do Murucutu/Aurá (BHMA) denunciam permanentemente a poluição das águas por chorume que desce do lixão do Aurá que se desloca em direção ao rio Guamá e que põe em risco os mananciais de Bolonha e Água Preta, na Bacia do Murucutu, que abastecem 75\% de Belém e Ananindeua (MARQUES et al., 2015).

A problemática aumenta ainda mais em função do processo de expansão urbana crescente e desordenada nos municípios de Belém e Ananindeua, levando ao surgimento de bairros, conjuntos residenciais e à multiplicação assentamentos espontâneos em seu entorno provocando uma grande pressão antrópica ao longo do entorno da BHMA (BORDALO, 1999).

A poluição das águas superficiais e subterrâneas em bacias pode se concentrar em razão dos fatores determinados e que influenciam diretamente no nível da água alcançado por uma enchente e/ou alagamento em razão das 
precipitações incidente e/ou dinâmica da enchente e vazante da maré (SANTOS et al., 2015). O objetivo neste trabalho foi zonear áreas úmidas nas bacias hidrográficas dos rios Murucutu e Aurá para identificar áreas suscetíveis a contaminantes.

\section{MATERIAL E MÉTODOS}

$\mathrm{Na}$ primeira fase, foi estruturado um banco de dados através do Sistema de Informação Geográfica QGis 2.8, versão "Wien”, licenciado pela "General Public License" (GNU), que conjuga funções de processamento de imagens, análises espaciais, modelagem numérica de terreno e consulta a banco de dados espaciais.

$\mathrm{Na}$ segunda fase, realizou-se preparação e extração de dados das bacias e redes de drenagens a partir dos MDE-SRTM. Utilizou-se ainda o MDE para elaboração de mapas de declividade e altimetria do terreno que foram reclassificadas atribuindo-se a todos o Datum de referencia WGS84, Fuso 22S. Nesta etapa, utilizou-se o conjunto de ferramentas do complemento "Terrain Analysis Using Digital Elevation Models" (TauDEM), sobre a plataforma QGis 2.8, que possibilita a análise de terreno, extração de informações hidrológicas da topografia, dentre outros (BIELENKI, 2012; BOSSLE, 2015).

Como última etapa, realizou-se o mapeamento de áreas úmidas na BHMA através dos cruzamentos geoespaciais dos Planos de Informações (PIs) raster, obtidos a partir do estabelecimento de um arquivo de regras no SIG. Ainda nesta etapa, foram elaborados mapas temáticos para representar espacialmente as bacias, redes de drenagens e uso e cobertura da terra, este último, usando informações disponíveis pelo TerraClass (INPE, 2010), onde fez-se o recorte e análise das bacias considerando o uso e cobertura da terra da BHMA.

Nos cruzamentos geoespaciais utilizou-se o método de Análise Hierárquica Ponderada - AHP. O AHP é uma técnica de análise de decisão e planejamento de múltiplos critérios desenvolvidos por SAATY (1977), em resposta ao planejamento de contingência empresarial, tomada de decisão, resolução de conflitos (TOSI et al., 2014). Esse método consiste na elaboração de uma escala de importância entre os critérios físicos utilizados na análise deste estudo. A Figura 1 consiste no diagrama metodológico para identificar áreas úmidas suscetíveis a contaminantes na BHMA.
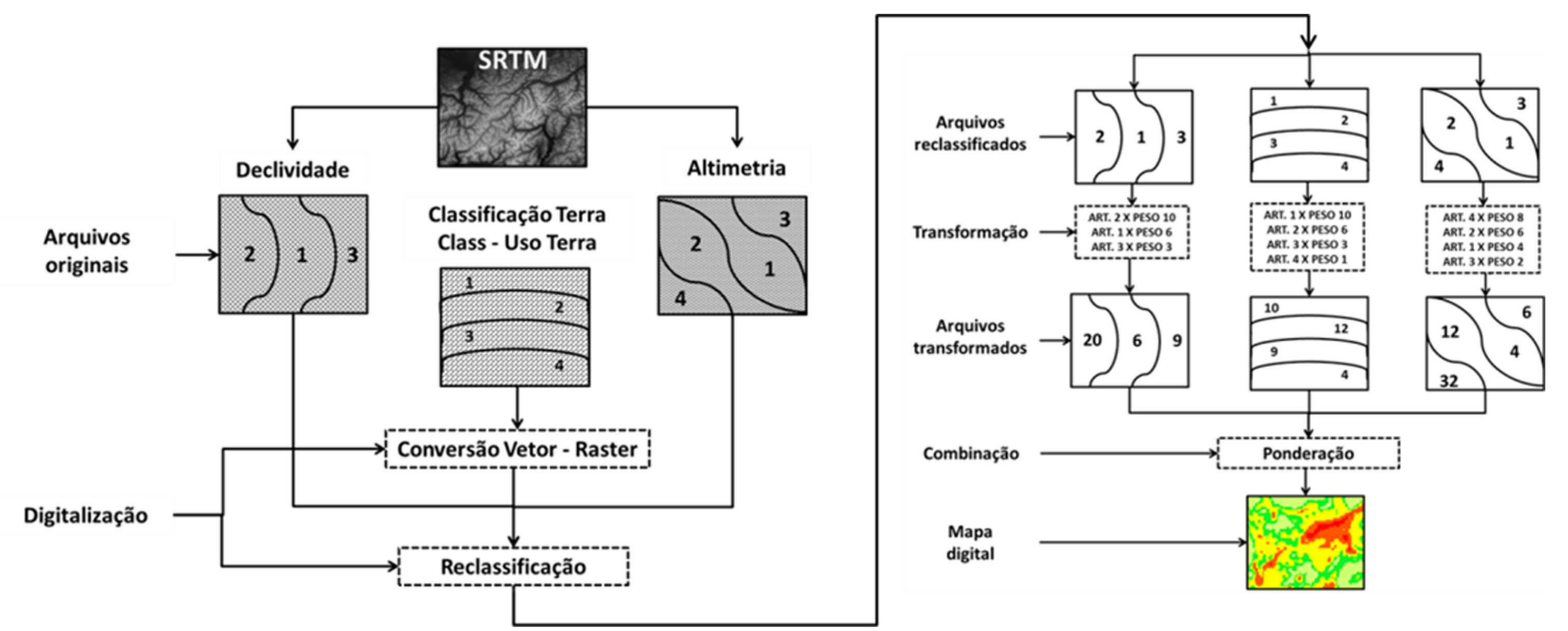

FIGURA 1 - Diagrama metodológico de Análise Hierarquicamente Ponderada (AHP).

Para obtenção das áreas úmidas, foi realizada a análise multicritério, que é o mapeamento de variáveis através de planos de informações (PIs) e nas definições 
de pesos para cada atributo, considerando suas influências nos processos de acúmulo de água, conforme a Tabela 1, 2 e 3.

TABELA 1 - Pesos atribuídos para cada classe de declividade.

\begin{tabular}{c|c}
\hline Classes de Declividade (\%) & Peso \\
\hline Plano & 10 \\
Suave ondulado & 7 \\
Ondulado & 5 \\
Forte ondulado & 4 \\
\hline
\end{tabular}

Fonte: Adaptado de DALFI et al. (2013).

A forma de ocupação da terra influencia na infiltração e escoamento superficial da água. Na área de estudo a maior impermeabilidade está presente na mancha urbana (área antropizadas) e no "Lixão do Aurá", que tendem a acumular água e provocar o escoamento para as bacias em análise. Foram atribuídos os seguintes valores de peso a cada classe de uso da terra (Tabela 2).

TABELA 2 - Pesos atribuídos para cada classe de uso e cobertura da terra.

\begin{tabular}{c|c}
\hline Classe de Uso terra & Peso \\
\hline Hidrografia & 5 \\
Várzea & 4 \\
Áreas antropizadas & 3 \\
Vegetação secundária & 2 \\
Vegetação & 1 \\
\hline
\end{tabular}

Fonte Adaptado de DALFI et al., 2013.

$\mathrm{Na}$ altimetria há relação inversa com o risco de poluição das áreas úmidas. Quanto maior a altitude, menor a probabilidade de existir áreas úmidas, devido à ação da gravidade que canaliza a água para as regiões mais baixas. Com as alturas identificadas através MDE, foram atribuídos os seguintes valores de peso a cada classe de altitude, de acordo com a Tabela 3.

TABELA 3 - Pesos atribuídos para cada classe de altitude

\begin{tabular}{c|c}
\hline Classes de Altimetria $(\mathbf{m})$ & Peso \\
\hline $0-11$ & 10 \\
$11-18$ & 9 \\
$18-23$ & 6 \\
$23-31$ & 4 \\
$31-51$ & 1 \\
\hline
\end{tabular}

Fonte Adaptado de DALFI et al. (2013).

Os mapas foram sobrepostos entre si sendo calculada a média ponderada do valor de prioridades dos pixels correspondendo basicamente ao somatório dos valores multiplicado por seus respectivos pesos divido pelo somatório dos pesos (Equação 1).

$$
\begin{gathered}
M p=\frac{X_{1} P_{1}+X_{2} P_{2} \ldots X_{n} P_{n}}{P_{1}+P_{2}+\ldots P_{n}} \\
M p=\frac{\sum_{i=1}^{n} X_{i} P_{i}}{\sum_{i=1}^{n} P_{i}}
\end{gathered}
$$


Em que: Xn são Planos de Informações e Pn são os Pesos de ponderação dos planos de informações.

$\mathrm{Na}$ Figura 2 estão ilustrados os procedimentos de álgebra de mapas para delimitação de áreas de interesse, contendo os critérios de ponderações na geração das zonas úmidas.

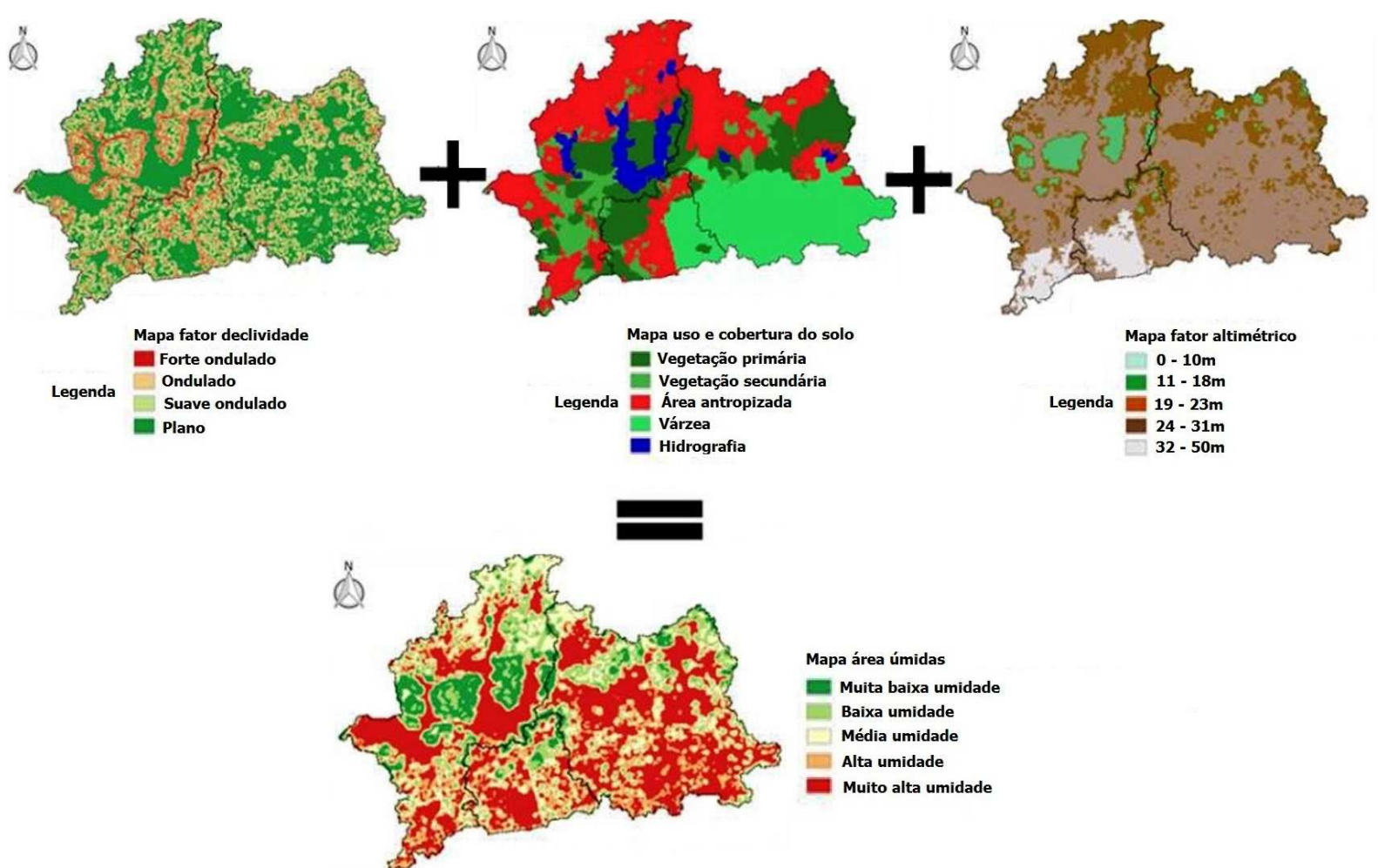

FIGURA 2 - Esquema de elaboração de mapa temático de áreas úmidas na BHMA.

\section{Área de estudo}

A área de estudo abrange as bacias hidrográficas dos rios Murucutu e Aurá (BHMA). Nestas regiões está localizado o aterro sanitário do Aurá, conhecido como "Lixão do Aurá," instituído em 1987, e a Área de Proteção Ambiental de Belém (APA), onde está inserido o sistema ambiental do Utinga, que é composto pelos Lagos Bolonha e Água Preta, responsáveis por parte significativa do abastecimento de água da região metropolitana de Belém (Figura 3). A bacia é circundada por áreas de vegetação nativa e áreas remanescentes da floresta amazônica (GOUVEIA et al., 2013). 


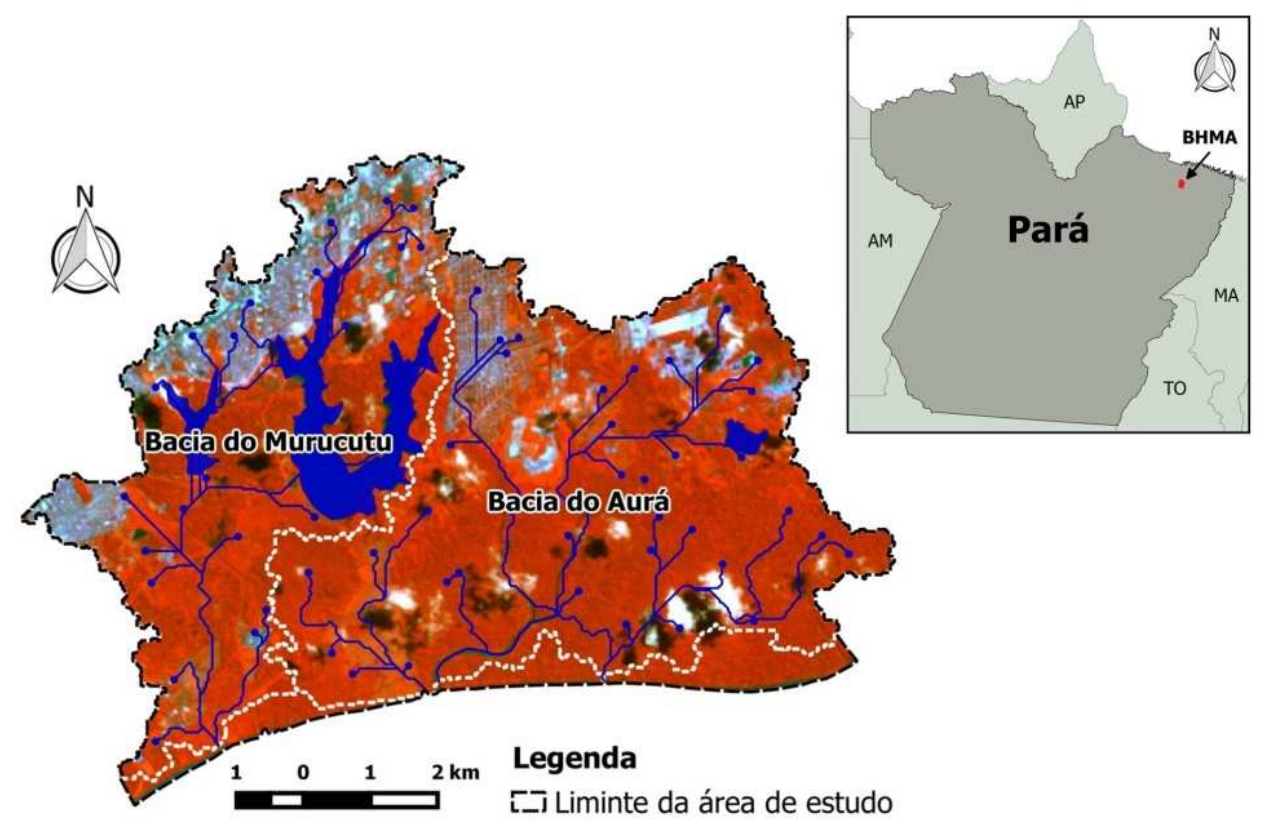

FIGURA 3 - Localização da área de estudo.

Fonte: SANTOS et al. (2015).

\section{RESULTADOS E DISCUSSÃO}

$\mathrm{Na}$ análise das classes de declividade identificou-se que a área em análise possui $34,68 \mathrm{~km}^{2}$ de área plana com cotas topográficas relativamente baixas, com menos de 15 metros. A área de várzea tem uma extensão territorial de $16,03 \mathrm{~km}^{2} \mathrm{e} a$ hidrografia ocupa uma área de $3,57 \mathrm{~km}^{2}$. As classes de várzea e hidrografia $(19,60$ $\mathrm{km}^{2}$ ) são as áreas que correspondem à extensão territorial das áreas sujeita a enchente e/ou alagamento, correspondendo às áreas úmidas da BHMA. As áreas úmidas conjugam as características de serem regiões de altimetria variando de 0 a $10 \mathrm{~m}$ e terreno de várzea, correspondendo respectivamente a $39,38 \mathrm{~km}^{2}$ e $6,62 \mathrm{~km}^{2}$.

No caso da BHMA as áreas úmidas ocorrem em razão da extensão territorial de várzea e com hidrografia e sobre influência do ciclo de marés de baixar mar e preamar, correspondendo a território de $4,54 \mathrm{~km}^{2}$. Contudo, independente do status de conservação da BHMA, identificou-se em todas as classes de uso e cobertura áreas com característica físicas serem áreas propícias de umidade, correspondendo a $10,5 \mathrm{~km}^{2}$, principalmente em razão de essa região ser de baixa altimetria e densamente drenada com 87.771,97 m de canais hidrográficos (SANTOS et al., 2015). Na Figura 4 apresentam-se as zonas: de muito alta e de alta umidade que estão sob influência de áreas de várzea pela rede hidrográfica. 


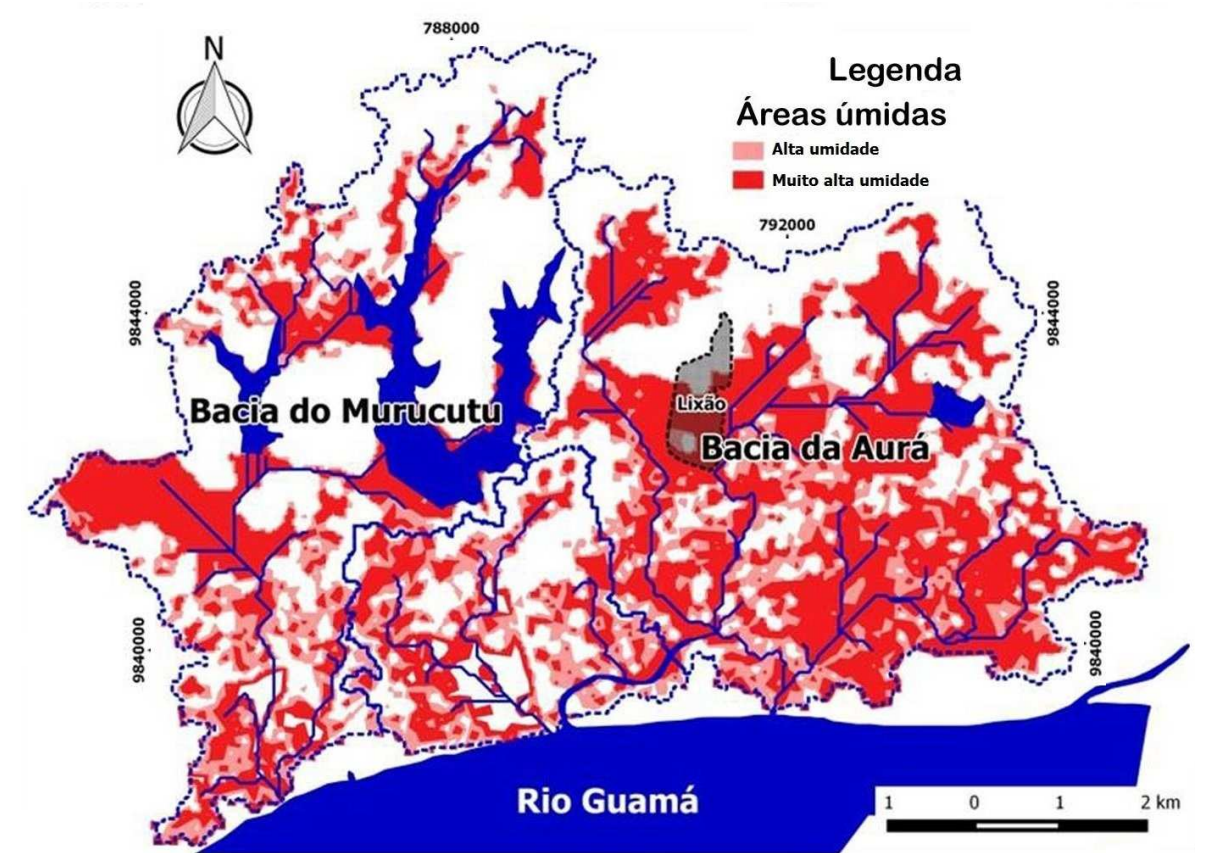

FIGURA 4 - Zonas úmidas na BHMA suscetíveis a contaminantes.

Com a análise identificou-se que 18,6\% da BHMA $\left(13,25 \mathrm{~km}^{2}\right)$ foi classificada em zona de Muito alta umidade e, 37,2\% (26,5 km²) em zona de Alta umidade, ou seja, cerca de $56,0 \%$ da BHMA é suscetível a contaminantes. Essas zonas representam as áreas baixas e planas mais propícias à acumulação de água e, por conseguinte transporte de contaminantes de resíduos líquidos e sólidos.

Ao observar a Figura 5, nota-se um ponto de cruzamento entre as áreas úmidas das bacias do Murucutu e Aurá, o qual encontra-se a uma distância de 1,4 km do "Lixão do Aurá". Esse lixão, de acordo com resultados de Marques et al. (2015), evidenciava problemas ambientais, principalmente por resíduos líquidos.

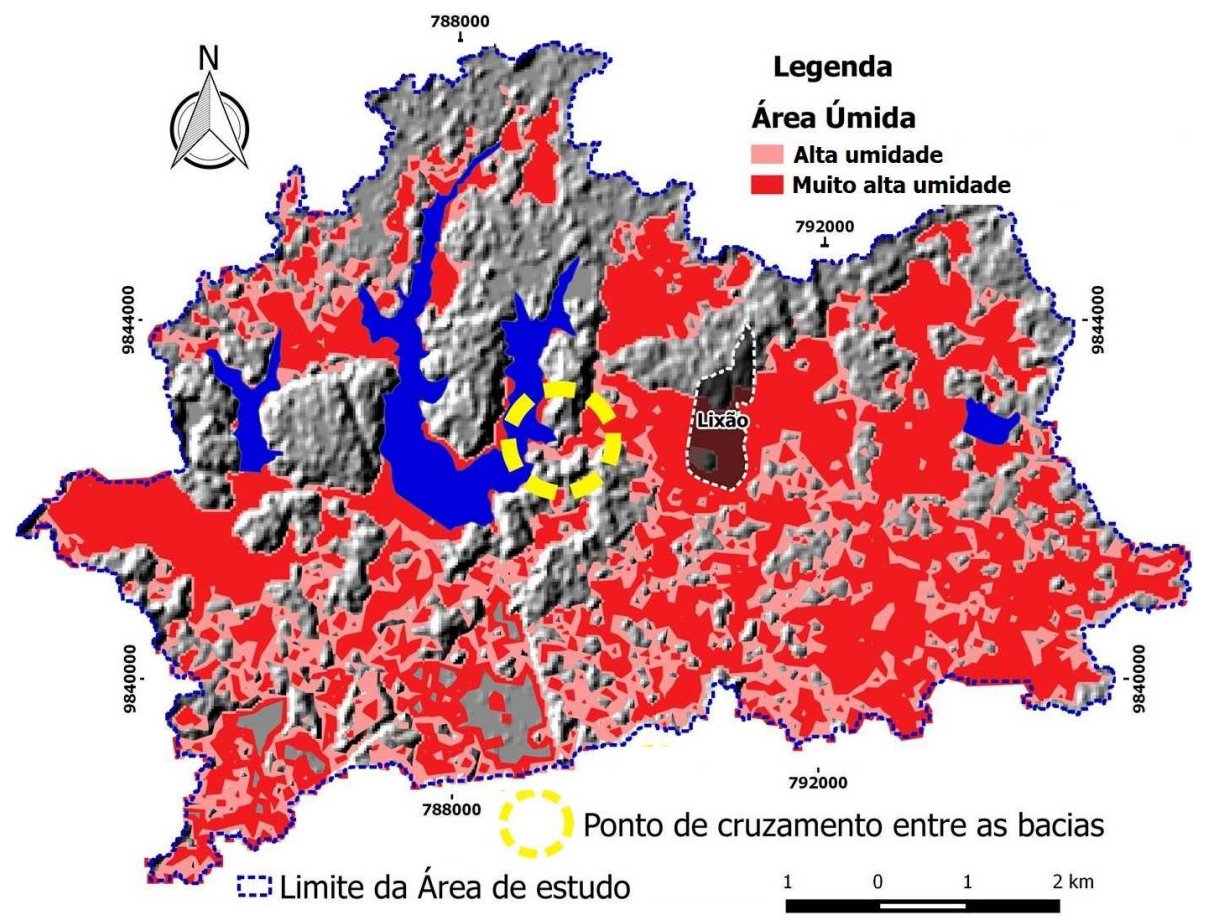

FIGURA 5 - Ponto de cruzamento das áreas úmidas na BHMA. 
A zona de Muito alta umidade, em razão do acúmulo de água, é um ambiente sensível à poluição ambiental, principalmente aquelas áreas que estão próximas ao "Lixão do Aurá" (polígono preto), conforme Figura 5. Conforme Matos et al. (2011), na bacia hidrográfica do Aurá ocorrem diferenças de concentrações de chorume na rede de drenagem, dependendo da distância do lixão, sendo os rios mais próximos os receptores primários, os quais são mais vulneráveis a contaminação ambiental pelos fluxos e refluxos de marés.

Neste contexto, as zonas com Muita alta e Alta umidade estão suscetíveis a contaminantes em razão do carreamento dos poluentes do "Lixão do Aurá". O ponto de cruzamento entre as bacias do Murucutu e Aurá evidencia que esta contaminação é potencializada pelo processo de transporte de chorume na BHMA. Vale destacar que os efeitos desses contaminantes podem ainda afetar os mananciais Bolonha e Água Preta, importantes reservatórios no abastecimento de água potável para a grande Belém, alimentados frequentemente pelo bombeamento do rio Guamá.

Além disso, essas duas zonas úmidas estão mais suscetíveis alagamento e/ou inundação em eventos de chuvas extremas e marés altas, potencializando os danos ambientais e perigo à saúde pública. Esses resultados corroboram com Marques et al. (2015), que identificou Índice de Qualidade de Aterro (IQAR) do Aurá da ordem de 2,7, indicando valores abaixo do índice recomendado pela Lei $\mathrm{n}^{\circ}$ $12.305 / 2010$.

Portanto, as áreas úmidas são ecossistemas acumuladores naturais de resíduos de origem inorgânica e/ou orgânica por inundações e/ou alagamento durante intensos eventos pluviais (STRZEBOŃSKA et al. 2015). Assim, Siqueira e Aprile (2013) destacam que a pluma de chorume que desce do Aurá pode gerar um risco potencial de contaminação. Segundo SOUZA \& ANJOS (2004) as contenções não oferecem uma proteção efetiva à penetração de contaminantes.

Os resultados obtidos com a análise de multicritério foram eficientes, pois integram variáveis biofísicas que apontam possíveis suscetibilidades ao chorume do Aurá pelo alagamento ou inundação. Assim, nas zonas úmidas a percolação e escoamento do chorume podem, inclusive, serem transportados até a bacia do rio Guamá.

\section{CONCLUSÃO}

Com base nos resultados obtidos neste estudo foi possível identificar as áreas úmidas (baixas e planas) na BHMA baixas com as seguintes conclusões:

- Mais da metade da Bacia Hidrográfica dos rios Murucutu e Aurá possui suscetibilidade a contaminantes, que pode ser intensificada em eventos de chuvas intensas e marés altas;

- O ponto de conexão entre as bacias dos rios Murucutu e Aurá evidenciam efeitos danosos por contaminantes que podem atingir a bacia do rio Guamá;

- A aplicação das geotecnologias pode ser uma ferramenta de análise de contaminação em bacia hidrográfica. 


\section{AGRADECIMENTOS}

Os autores expressam seus agradecimentos ao Programa de Mestrado em Ciências Ambientais da Universidade do Estado do Pará (UEPA), bem como a Empresa Brasileira de Pesquisa Agropecuária (Embrapa Amazônia Oriental), pela oportunidade de realização deste trabalho em parceria científica.

\section{REFERÊNCIAS}

ARAÚJO, L. A.; SOUSA, S. N.; LOBATO, V. C. Análise da disposição do lixo na cidade de Belém-PA: o caso do "Lixão do Aurá". Revista Para Onde!?, V.1, no 6, p. 62- 77, 2010.

BIELENKI, J. Geoprocessamento e recursos hídricos: aplicações práticas. São Paulo. EduFCar. 2012. 257 p.

BORDALO, C. Uma Reflexão de Proteção dos Mananciais de Região Metropolitana de Belém - PA (1984 - 2004). Dissertação de Doutorado. FCT/UNESP. Presidente Prudente, 1999.

BOSSLE, R. C. Qgis e Geoprocessamento na Prática. São José dos Pinhais: Edição do Autor, 2015. 232p.

DALFI, R.L.; SANTOS, A. R,; CAMPOS, R. F.; MOREIRA, T. R.; EUGENIO, F. C.; DOS SANTOS, G. M. Cenários distintos no mapeamento de áreas de inundação nos bairros do município de Alegre, ES. Caderno de Geociências, v. 10, n. 2, p. 78-86, 2013.

GOUVEIA, R. G.; GALVANIN, E. A.; NEVES, S. M. Aplicação do índice de transformação antrópica na análise multitemporal da bacia do córrego do Bezerro Vermelho em Tangará da Serra-MT. Revista Árvore [online]. 2013, vol.37, n.6, pp. 1045-1054. ISSN 0100-6762. Disponível em:< http://www.scielo.br/pdf/rarv/v37n6/06.pdf>. Acesso em: 20 Jun. 2015.

MARQUES, L. C. A.; PONTES, A. N.; GUTIERREZ, L. A. C. L.; BANNACH, M. P. AVALIAÇÃO DO ESPAÇO DE DESTINAÇÃO FINAL DE RESÍDUOS SÓLIDOS URBANOS DA CIDADE DE BELÉM, PARÁ. Enciclopédia Biosfera, v. 11, p. 28742883, 2015.

MATOS, F. O.; SOUSA, L. P.; MORALES, G. P.; VASCONCELOS, R. C.; MOURA, Q. L. Influencia da Maré na Dissolução de Poluentes Gerados no Depósito de Resíduos Sólidos da Região Metropolitana de Belém-Pa. Enciclopédia Biosfera, Centro Científico Conhecer - Goiânia, vol.7, N.13; 2011 Pág. 1174, 2011.

MELO, F. A.; SARMANHO, S. S.; MORALES, G. P.; RIBEIRO, H. M.; PIRATOVA, A. A. Análise de Suscetibilidade Erosiva no Município de Barcarena - Pa. Enciclopédia Biosfera, Centro Científico Conhecer - Goiânia, v.11 n.22; p, 2015.

PARÁ. Ministério Público. Termo de ajustamento de conduta para tratamento da gestão integrada de resíduos sólidos. Belém, 2013. Disponível em: <http://www.mp.pa.gov.br/upload/TAC_RESIDUOS\%20SOLIDOS.PDF>. Acesso em: 22 Mai. 2015. 
PIEDADE, M. T. Organismos aquáticos e de áreas úmidas em uma Amazônia em transição. Ciência Cultura. [online]. 2014, vol.66, n.3, pp. 34-40. ISSN 2317-6660. Disponível em:< http://cienciaecultura.bvs.br/pdf/cic/v66n3/v66n3a13.pdf >. Acesso em 30 jun. 2015.

SAATY.T. H. A scaling method form priorities in hierarquical structures. Journal of Mathematical Psychology, v.15, n 3, p.234-281, 1977.

SANTOS, A. R.; LOUZADA, F. L. R. O.; EUGENIO, F. C.. ArcGIS 9.3 total: aplicações para dados espaciais. Alegre, ES: Ciências Agrárias Universidade Federal do Espírito Santo/CAUFES,. 2010180 p. Disponível em:< http://www.mundogeomatica.com.br/Livros/Livro_ArcGIS\%209.3_Aplicacoes_para_d ados_espaciais/Livro_arcgis93_Total.pdf >. Acesso em: 12 Jun. 2015.

SANTOS, L. S.; GUTIERREZ, C. B. B.; DIAS, N. M.; PONTES, A. N. Análise Espacial na Gestão de Recursos Hídricos: Bacia Hidrográfica do Rio Uriboca, Belém, Pará. Enciclopédia Biosfera, Centro Científico Conhecer - Goiânia, v.11 n.22; p. 2015.

SANTOS, F. A.; ROCHA, E; J. Alagamento e Inundação em Áreas Urbanas. Estudo de Caso: Cidade de Belém. Revista GeoAmazônia, Belém, v. 02, n. 2, p. 33 - 55, jul./dez. 2013.

SIQUEIRA, G.W.; APRILE, F. Avaliação de risco ambiental ou contaminação metálica e material orgânico em sedimentos da bacia do Rio Aurá, Região Metropolitana de Belém-PA. Revista Acta Amazônica, vol. 43, no. 1, p. 51-62, 2013.

SOUZA, E. L.; ANJOS, G. C. Contaminação das Águas Subterrâneas: Uma Visão Parcial da Situação de Belém e dos Problemas Decorrentes In: UHLY, Steven; SOUZA, Eliene Lopes de (organizadores). A Questão da Água na Grande Belém. Belém: Casa de Estudos Germânicos, 2004.

STEINKE, V. A.; SAITO, C. H. Exportação de Carga Poluidora para Identificação de Áreas Úmidas Sob Risco Ambiental na Bacia Hidrográfica da Lagoa Mirim. Revista Sociedade \& Natureza, On-line version ISSN 1982-4513. Uberlândia, 20 (2): 43-67, DEZ, 2008.

STRZEBOŃSKA, M.; KOSTKA, A.; RYBICKA, E. H.; KRZEMIŃSKA, E. J. Effect of Flooding on Heavy Metals Contamination of Vistula Floodplain Sediments in Cracow: historical Mining and Smelting as the Most Important Source of Pollution. Polish Journal of Environmental Studies, vol. 24, n. 3, p. 1317-1326, Crodóvia-Polônia, 2015.

TOSI, R. B.; NÄÄS, I. A,; GARCIA. R. Viabilidade Econômica para a Aplicação das Normas Brasileiras na Produção de Frangos de Corte. Enciclopédia Biosfera, Centro Científico Conhecer - Goiânia, v.10, n.18; p. 2014. 